\title{
Ramón Gómez de la Serna: El alma de los objetos. Minificciones. Edición de Rafael Cabañas Alamán. León: Eolas Ediciones, 2019.
}

A pesar de haber pasado más de cien años desde la publicación de las primeras greguerías y minificciones de Ramón Gómez de la Serna, sus textos no dejan de ser actuales y siguen dejando resonancias en la actualidad literaria. Siendo uno de los pioneros de las vanguardias hispánicas, funda en 1908 la revista Prometeo, donde publica el Manifiesto futurista de Marinetti, funda en 1914 su archiconocida tertulia del Café Pombo, participa en 1915 en la organización de la primera exposición cubista en Madrid, y crea en 1917 la greguería, manifestación textual par excellence vanguardista. Pero estos datos son sumamente escasos para ilustrar su propuesta intelectual, estética y literaria, en resumidas cuentas, su "Ramonismo". Este nuevo tomo, perteneciente a la colección "Las puertas de lo insólito. Narrativas de lo posible" de la editorial leonesa Eolas, nos presenta una asombrosa vertiente del pensamiento del escritor, su fetichismo de los objetos, complementado por un gesto duchampiano: el hacer de los objetos cotidianos objetos artísticos, más en concreto, objetos literarios.

El prólogo sugestivo del editor Rafael Cabañas Alamán, investigador especializado en la obra y pensamiento de Gómez de la Serna, ilumina la relación del autor con el realismo y la realidad, que justifica perfectamente el lugar de El alma de los objetos en esta colección organizada en torno al concepto de lo insólito. Partiendo de los manuscritos que se encuentran clasificados en la sección de "Prólogos" de la carpeta "Realismo" de la Biblioteca Hillman de la Universidad de Pittsburgh, se evidencia el desacuerdo del autor con la estética del realismo: "Para él, lo más importante era hacer literatura partiendo de la realidad pero representando las vertientes más insólitas de la misma, buscando la originalidad y teniendo siempre presente el factor sorpresa y la novedad" (8). La más sugerente es, en este sentido, la nota 7: "Realismo. No puede ser la literatura, que es un triunfo del genio o del ingenio, la presentación reincitiva y contumaz del mundo analfabético y vulgar".

Esta actitud antirrealista del autor - y de las vanguardias históricas en general—, que ha tenido un impacto enorme en las posteriores literaturas hispánicas, asimismo es tangible en su relación con los objetos, protagonistas, junto con el alma, de las minificciones aquí reunidas. El editor cita de un ensayo fundamental del autor, escrito en 1934 y titulado "Las cosas y «el ello»", donde se subraya este énfasis en la cosa o el objeto, y aparece el autor como "psicólogo de los mismos [objetos] en cuanto a la capacidad afectiva que reconoce sentir por ellos" (9). Es más, Cabañas Alamán considera que hay ciertos pasajes del texto donde el autor explica cómo logra conectar su alma con la de los objetos, para llegar a la conclusión de que Gómez de la Serna "parte de imágenes de objetos tangibles, cotidianos, pero le da un giro considerable a la realidad que observa bajo las premisas del «antirrealismo artístico» que tanto apoya” (9).

Esta idea de la relación entre el alma y los objetos en la obra de Ramón Gómez de la Serna, que fue comentada anteriormente por varios pensadores, entre ellos, Jorge Luis Borges, Gonzalo Torrente Ballester y Rafael Conte, sirve como fundamento de coleccionar los textos del tomo tras una lectura pormenorizada de numerosas publicaciones del autor - Greguerías (1917), Muestrario (1918), Greguerías selectas (1919), Libro nuevo (1920), Disparates (1921), Variaciones (1922), El alba y otras cosas (1923), Ramonismo (1923), Gollerías (1926, 1946), Los muertos, las muertas y otras fantasmagorías (1935, 1942, 1945), Total de Greguerías $(1955,1962)$ y Caprichos (1956) - y también sirve como punto de partida para la creación de 
cuatro apartados temáticos: "El optimismo vitalista", "Los objetos del alma", "Los objetos insólitos" y "Perspectivas de la muerte", terminando cada uno con textos inéditos no recogidos en Obras completas del autor, transcritos directamente de las notas manuscritas de la Biblioteca de la Universidad de Pittsburgh.

El título del primer apartado, "El optimismo vitalista", se inspira en el ensayo ya mencionado de "Las cosas y «el ello»", donde Gómez de la Serna apunta al "optimismo de las cosas". Leyendo los primeros textos se notan los rasgos comunes de estas microtextualidades que caracterizarán el tomo entero: el autor, a través de analogías y comparaciones, humaniza los objetos, y si aparece el hombre, siempre es deshumanizado, cosificado. A pesar de que el editor haya organizado este apartado en torno al concepto del optimismo, destaca en su "Prólogo" que la vitalidad y diversión que implica esconde un humor serio, además de indicar, usando las palabras de Pedro Salinas, el deseo de "desviar el espíritu y su atención de la terrible realidad aniquiladora" (12). Detrás del humor de los textos se halla pues una seriedad fundamental, que aparece metafóricamente, en objetos cotidianos que frustran la vida de los seres humanos (como pasa en "La corbata feliz"), o bien serán los humanos que aparecen como objetos sin alma (como en "Los dueños de la tienda de objetos de goma", para destacar solo unos ejemplos). El mejor texto, a la vez el más complejo y lúdico de este apartado es "La sensibilidad de los cuadros", donde aparece el yo autoral ante su propio retrato cubista con el que se comunica de forma telepática.

El título del segundo apartado, "Los objetos y el alma", de nuevo se inspira de un ensayo del autor, "Alma" (1912), donde aparece este como imagen multiforme, vinculada a varios objetos a la vez. Este animismo puebla todos los objetos aquí mencionados: "los objetos de las minificciones de este apartado poseen «alma», con frecuencia citada textualmente, y contienen una evidente carga de afectividad y sentimientos" (14). Y, de hecho, son quizás estos textos que ilustran mejor las propiedades principales del alma intangible e inmaterial, reflejada siempre en la materialidad de los objetos. El autor indaga la cuestión del entendimiento mutuo entre humanos y objetos (y aún animales, que se clasificarían igualmente como "cosas"), ejemplo de ello lo encontramos en una de sus greguerías tempranas: “¿Hasta dónde nos sospechan los animales y las cosas? Todo ello está lleno de magnetismo y eso llena a todos de grandes y raras dificultades" (94). Esta oscilación entre lo material y lo inmaterial del objeto-alma o almaobjeto, dependiendo de la perspectiva, igualmente problematiza la relación entre vida y muerte, en otra greguería: "Al que descompone un reloj le queda el arrepimiento de haber matado algo, de haber cometido sacrilegio... Es irreparable su muerte desde que se le mata" (90).

El tercer apartado, "Los objetos insólitos", ofrece una mezcla de lo cotidiano con lo insólito, lo absurdo y aun lo grotesco. El concepto de lo absurdo el editor lo rescata de nuevo de un texto del autor de El libro mudo (Secretos) (1911): "Ramón, seamos ante todo absurdos, inexplicablemente absurdos... habremos roto una trabazón, habremos acabado con un infarto... Nos habremos intricado más" (15). Estas minificciones, según el propio Cabañas Alamán, se basan en el principio de la incongruencia, recurso literario propio de la ficción, siendo lo absurdo, con las palabras del autor, "una protesta contra la vida, objetivando sus obsesiones, mostrando lo que hay junto a los faroles y los árboles, al gran supuesto que les rodee como un pensamiento" (16). Los objetos insólitos que pueblan los textos de este apartado no son, en realidad, insólitos; al contrario, Gómez de la Serna muestra cómo lo insólito reina los días cotidianos mostrando un lado no-funcional o no-utilitario de las cosas que enumera: cuadros 
que nunca pueden estar derechos, los zapatos que andan solos, la bola de billar que huye, o el diccionario de lo que no existe. El reloj y el espejo son los dos objetos más inquietantes, ya que estos recurren no solo en este sino en todos los apartados del libro, saturados de significados simbólicos: "marcan el devenir del ser humano ante la muerte", opina el editor (17).

Y, de hecho, este será el tema principal del último capítulo de El alma de los objetos: "Perspectivas de la muerte". Cabañas Alamán recurre aquí a la explicación que ofrece el autor sobre su libro Automoribundia (1888-1948), donde afirma que en todas las páginas que había escrito en su vida hay un fondo autobiográfico, hasta cuando escribe sobre los objetos, a los cuales "otorga el poder de proyectar en sí mismas la propia muerte en cualquiera de sus diferentes manifestaciones, ya sea como portadoras o como receptoras de esta" (16). En este apartado llegamos a conocer objetos cotidianos pero potencialmente peligrosos para el hombre, y no solo los agudos como la navaja de afeitar o los que tengan que ver directamente con la muerte como los objetos funerarios, sino también otros que son aparentemente inocentes, como los trajes o las bufandas, que amenazan no tanto la vida humana como el concepto de lo humano; es decir, dejan paso, de nuevo, al predominio de lo grotesco, lo absurdo y lo insólito.

El gesto duchampiano al principio mencionado, el de hacer de los objetos cotidianos objetos artísticos, literarios, de darlos vida, otra vida (el valor de objeto literario, de ficción) a pesar de su cotidianeidad, muestra una intención estética propiamente vanguardista, el deseo de la distorsión de la realidad, necesaria para revelar — un tanto paradójicamente — su lado real, auténtico: lo inmaterial. No obstante, este apego a los objetos, a las cosas y los humanos igualmente evidencia la imposibilidad de separarse de la realidad inmediata. De esta forma suma el editor de El alma de los objetos la relación de Ramón Gómez de la Serna con lo insólito:

escritor de gran modernidad, adelantado a su tiempo, que desde el antirrealismo artístico y el humor juega con una amplia gama de las vertientes de lo insólito distorsionadoras de la realidad - lo irracional, lo absurdo, la incongruencia, lo fantástico y lo surrealista-. Su búsqueda de nuevas formas, de espacio de fantasmagoría y de ilusión, ofrece una visión iluminadora de la vida, en esta ocasión a través de los objetos, de la relevancia y la singularidad que despliegan en sus minificciones". (20)

Esta compilación temática que nos ofrece Rafael Cabañas Alamán, admitiendo la arbitrariedad de la agrupación y sugiriendo una posible flexibilidad en el intercambio de los textos entre los diferentes apartados, es una muestra de textos cortos pero sumamente profundos. Se ofrece pues un punto de partida excelente para los menos iniciados en la obra de este autor prolífero, y asimismo se sirve como material de investigación abundante para los más experimentados.

Petra Báder

Universidad Eötvös Loránd bader.petra@btk.elte.hu

DOI: $\underline{\text { https://doi.org/10.24029/1ejana.2020.14.1662 }}$

Recibido: el 31 de agosto de 2020

Aceptado: el 5 de enero de 2021

Publicado: el 26 de febrero de 2021 
(C) Petra Báder

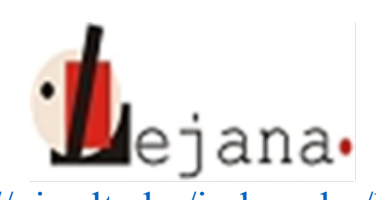

http://ojs.elte.hu/index.php/lejana

Universidad Eötvös Loránd, Departamento de Español, 1088 Budapest, Múzeum krt. 4/C 